\title{
Un viejo drama humanitario recién descubierto que desnuda hipocresías e incapacidades políticas
}

Con fecha 12 de junio del presente año, todos los centroamericanos fuimos sorprendidos con la alarma difundida por el Gobierno de los Estados Unidos de América, sobre una "crisis humanitaria" que experimentaban, ya para esa fecha, un elevado número de niños y niñas originarios de nuestros países - principalmente de Guatemala, El Salvador y Honduras- que, habiendo migrado de manera irregular y sin acompañamiento de familiares, se encontraban hacinados en los albergues de la patrulla fronteriza, dependiente del Departamento de Seguridad Nacional estadounidense, en Arizona, y en una base militar en California.

Ciertamente, las cifras de niños hacinados en tales albergues, proporcionadas y rápidamente difundas por los medios de comunicación, haciendo eco oportuno a toda información proveniente de fuentes gubernamentales estadounidenses, son elevadas. Se indicaba, en esa fecha, que se trataba de más de 1000 niños, número que había incrementado a un poco más de 1154 niños y niñas al día siguiente; de ellos entre 337 a 379 habían sido identificados como salvadoreños, y en su mayoría (214) eran varones. Las condiciones en las que se encontraban los niños eran descritas como calamitosas, propias de hacinamiento y de encarcelamiento: durmiendo -literalmente- en el suelo, y cubiertos con delgados cobertores de aluminio, en espacios estrechos -evidentemente bodegas-, con limitadas posibilidades de movilidad y circulación de aire fresco, lo que ya había desatado alarma de contagio de enfermedades respiratorias. De acuerdo a las autoridades estadounidenses, se calculaba un incremento de llegada diario de 400 niños por día a la frontera del país, por lo que se preparaban para más albergues en California, Oklahoma y Florida.

La alarma de crisis humanitaria fue dada por las más altas autoridades del Gobierno norteamericano. Nada menos que el vicepresidente, Joe Biden, se encarga oficialmente de señalar la gravedad de la situación y convoca de urgencia a una reunión que se celebraría en Guatemala el viernes 17 de junio, con los presidentes de Guatemala, de El Salvador y representantes del Gobierno de Honduras. ¿En qué consiste realmente la alarma de crisis humanitaria? ¿Es la cantidad de niños y niñas migrantes que llegan sin acompañantes adultos? ¿Es el estado calamitoso en que se los mantiene en los albergues? ¿Es la cantidad de albergues que tienen que abrir o los costos que esto les ocasiona o el costo que toda la atención ocasiona? ¿Serán los costos de administración y de procedimientos jurídicos para validar los pro- 
cesos de deportación que con alto grado de seguridad van a ocurrir? ¿O es que el grado de humanización por fin ha imperado y ahora el país del norte se ve conmovido por el sufrimiento de estos niños en los albergues o por los riesgos que atraviesan en el camino? Por más que cada una de esas preguntas sea revisada "al derecho y al revés", es difícil, viniendo del gobierno norteamericano, encontrar el sentido claro que quiere dársele a la afirmación de la emergencia. Pareciera ser que quiere presentarse el hecho como algo que sobrepasa las capacidades instaladas y los costos económicos de atención humanitaria y, por tanto, la situación humanitaria de niños, niñas y adolescentes está en riesgo. Nada más lejos de la realidad e igualmente lejos de una verdadera solución humanitaria que tenga en consideración el interés superior de la niñez.

Entre los años fiscales de 2008 al 2012, se produjo un incremento de 22271 detenciones y consecuente deportación de niñas y niños centroamericanos por parte de la Patrulla de Control de la Frontera. De acuerdo al Centro de Estudios para Género y Refugio de la Universidad de California, en 2012 fueron detenidos en la frontera estadounidense 13625 niños, de los cuales 6172 eran centroamericanos. Esta cifra incrementó fuertemente a 24668 en el año fiscal 2013, por lo que el Gobierno estadounidense pronosticó, desde principio del año 2014, una llegada a la frontera sur, de aproximadamente 60000 niños, cifra que ha estado siendo manejada como argumento de la gravedad de la crisis. Cabe preguntar, por un lado, si con esa previsión de datos no cabría planificar oportunamente, por parte del Gobierno y todas sus agencias de apoyo, la atención de dichos niños y niñas. Por otro lado, no cabría el argumento de la incapacidad económica del Gobierno estadounidense de atender situaciones humanitarias de emergencia. Esto es lo menos creíble. El Instituto Internacional de Investigaciones de la Paz (SIPRI), de Estocolmo, publicó -en su reporte anual de 2013- que el mundo en su conjunto gastó 1750 billones de dólares en sus ejercitos durante ese año, y que EE. UU. se mantuvo con el principal comprador de armas

Una pregunta consecuente es si el trato que siempre ha dado el Gobierno norteamericano al derecho de la niñez migrante a la reunificación familiar es realmente humano. al invertir 640 billones, lo que representa el $43 \%$ del gasto militar mundial. ¿Qué porcentaje de ese gasto costará atender humanitariamente a 60000 niños?

Los Gobiernos centroamericanos sostienen, y con mucha seguridad así es, que un elevado porcentaje de los niños que migran no acompañados tienen familiares en Estados Unidos y ello les concede el derecho a la reunificación familiar como parte del principio del "interés superior del niño" reconocido en la Convención Internacional de Derechos del Niño. Sobre esta base, un porcentaje elevadísimo de los niños detenidos en los albergues contaría con el derecho a procesos jurídicos hasta agotar los debidos procesos antes de definir su deportación. Sin embargo, la decisión del Gobierno norteamericano, que fue expuesta con contundencia ante los gobernantes de la región, es la deportación de todos los niños, pese al conocimiento cierto de los convenios y las leyes norteamericanas que abogan por los procesos respectivos en beneficio de la niñez. Una pregunta consecuente es si el trato que siempre ha dado 
el Gobierno norteamericano al derecho de la niñez migrante a la reunificación familiar es realmente humano. El Centro de Estudios para el Género y el Refugio, ya mencionado, indica -en su reporte de 2014, Un camino arriesgado. Niños, niñas y adolescentes migrantes. Navegando el Sistema de Inmigración de los Estados Unidos- que, cuando las autoridades estadounidenses de Inmigración detienen a los niños, estos ingresan en custodia del gobierno federal para incorporarlos en los procesos de deportación. El tratamiento que les dan es de "adultos en miniatura":
Ante una crisis humanitaria, la respuesta apropiada debería ser un trato humanitario consistente con los principios y derechos reconocidos internacionalmente, a los que sufren la crisis, particularmente si esas personas son niñas y niños. sin ningún derecho a la representación gratuita de un abogado o abogada y sin nadie que vele por sus intereses en el sistema legal norteamericano. Senala el mismo informe que hay un reconocimiento creciente en los Estados Unidos de las vulnerabilidades y necesidades especiales de los niños y las niñas inmigrantes, en el sistema de inmigración de ese país, especialmente de los que viajan solos. La Ley de Seguridad Nacional (Homeland Security Act, o HSA) del 2002 y la Ley de Reautorización William Wilberforce para la protección de Víctimas de Trata, de 2008, incluyen, por ejemplo, disposiciones que amplían las protecciones legales de los niños y las niñas en los procedimientos de inmigración, indicando el derecho a que se les brinde representación legal, a que se les asigne a alguien que vele por sus intereses. Sin embargo, esto no se ha aplicado con la niñez que se encuentra en estos momentos detenida por haber ingresado al país de manera irregular, y tampoco se han establecido criterios especiales para los niños y las niñas que buscan un estatus de refugio. El principio del interés superior del niño que se aplica en la asistencia social infantil y en el sistema de justicia penal juvenil norteamericano parece no ser vinculante en los procedimientos de inmigración de los niños y, por tanto, no se aplica. En estos casos, para evitar la deportación, un niño o una niña debe presentar defensas legales como un adulto tendría que hacerlo. ¿Dónde están entonces los principios y las actuaciones de justicia y humanidad mínimos, que den solvencia moral para hablar de crisis y drama humanitario de los niños y las niñas migrantes? Ante una crisis humanitaria, la respuesta apropiada debería ser un trato humanitario consistente con los principios y derechos reconocidos internacionalmente, a los que sufren la crisis, particularmente si esas personas son niñas y niños.

Otro elemento que puede agregarse como parte de la real crisis humanitaria que viven los niños migrantes es el maltrato y abuso del que son objeto en los lugares de detención, tanto en Estados Unidos como en México. Diferentes organizaciones norteamericanas en apoyo a los niños migrantes, entre ellos el Centro de Estudios Latinoamericanos de American University en Washington D. C., el Centro Nacional de Justicia para Migrantes, la organización Kids in Need of Defense (KIND) y el Centro de Estudios para Género y Refugio, ya mencionado, en diferentes ocasiones han presentado denuncias de maltratos y abusos de niños en albergues estadounidenses. La Comisión Interamericana de Derechos Humanos (CIDH) informó, la última semana de junio, que organizaciones civiles de Estados Unidos denunciaron 
116 casos de abusos sexuales, físicos y verbales hacia menores de edad por parte de agentes fronterizos estadounidenses. El relator sobre los derechos de los migrantes de la CIDH, Felipe González Morales, detalló que estos abusos sexuales fueron cometidos durante la detención, antes de llevarlos a los centros de reclusión.

En este burdo escenario de juegos políticos, queda desdibujado todo intento de responder con profundo sentido humano a las necesidades de aquellos que, por su edad, merecen la protección especial del Estado, sea este el de destino, de tránsito o de origen.
Ocultos en el discurso artificioso de la crisis humanitaria que dice lamentar el Gobierno norteamericano, se encuentran problemas de poder dentro de la política interna federal y de varios estados particulares, de corto y largo plazo en torno al tema de migración, en medio de los cuales el tema de la niñez migrante atrapada en la frontera estadounidense se ha convertido "deshumanizadamente" en moneda de cambio. La ley de reforma migratoria impulsada por el presidente Barack Obama y aprobada por el Senado en 2013 con mayoría Demócrata, no será aprobada por la Cámara de Representantes controlada por los republicanos, quienes han propuesto un texto diferente al aprobado. La reforma, que se conoce como Ley de Modernización de Inmigración, Seguridad Fronteriza y Oportunidad Económica, o S. 744, supondría un cambio, en muchos aspectos radical, en cómo se regula la inmigración. Afectaría a millones de indocumentados, a la seguridad fronteriza y a los caminos para emigrar y obtener visas de trabajo. Entre las medidas, destacan posibilidades de diferentes formas de regularización del estatus legal de cerca de once millones de indocumentados que hayan entrado hasta diciembre de 2011, pero simultáneamente se incorporan medidas de endurecimiento del control fronterizo y de procesos de inmigración, que buscan lograr un $90 \%$ de detenciones de personas que intentan ingresar ilegalmente a Estados Unidos. Busca también regular de manera estratégica el manejo de situaciones que a largo plazo se conviertan en problemas explosivos con una altísima población inmigrante indocumentada y que afectarían los intereses políticos de los partidos políticos ante la población norteamericana en diferentes estados.

El vínculo del discurso de la "crisis humanitaria" con el tema de la reforma migratoria, lo dejó claro el vicepresidente Biden ante los gobernantes de la región en la reunión sostenida en Guatemala. Les señaló que la llegada de niños migrantes a la frontera estadounidense, sin documentos y sin compañía de familiares, socavaría las posibilidades de que la reforma migratoria impulsada por el presidente Obama fuese aprobada por la Cámara de Representantes. El endurecimiento "ejemplarizante" del Gobierno de Obama ejecutado en directo y en vivo a través de los medios de comunicación resulta ser más un discurso para el público republicano de la Cámara de Representantes, quienes a través de su presidente, John Boehner, comunicaron en medio de la "crisis" al presidente Obama que de todas maneras la reforma migratoria aprobada en el Senado no sería aprobada en la Cámara.

Ante esta posición, con toda seguridad ya prevista como inevitable, y como parte de un juego calculado, el presidente Obama anunció el 30 de 
junio 2014, que aplicará medidas migratorias en la línea de la reforma que impulsa, mediante el recurso de "poderes presidenciales" (executive orders). Ya ha anunciado, por ejemplo, que aplicará el poder ejecutivo denominado Acción Diferida (DACA, por sus siglas en inglés) que fue aprobado el 15 de junio de 2013 y que beneficia desde entonces a más de 550000 jóvenes que llegaron al país de niños, mediante una semilegalización que les permite protección frente a una posible deportación y permiso de trabajo. Pero simultáneamente, ha anunciado también, teniendo como telón de fondo la crisis humanitaria de los niños migrantes, medidas de endurecimiento. Pedirá al Congreso dos mil millones de dólares para contener dicho flujo, mediante el envío de manera inmediata al sur de Texas, de agentes de la Policía de Fronteras que se encuentren en otra parte del país. Asimismo, se asignarán a la zona fronteriza jueces de inmigración que ahora están destinados en otra parte del país. En este burdo escenario de juegos políticos, queda desdibujado todo intento de responder con profundo sentido humano a las necesidades de aquellos que, por su edad, merecen la protección especial del Estado, sea este el de destino, de tránsito o de origen.

El drama y la crisis humanitaria de la migración infantil centroamericana existe, ciertamente, pero no para el Gobierno norteamericano, sino para la niñez que migra y para la que inevitablemente lo hará. Existe ante la incapacidad de cada uno de los Estados centroamericanos de contrarrestar las condiciones de exclusión social de la población y de brindar protección y seguridad a la niñez que se ve amenazada de diferentes formas por el crimen organizado y particularmente el accionar de las pandillas. Estudios realizados recientemente, por ejemplo, por la UCA -Diagnósticos sobre caracterización de la población salvadoreña retornada con necesidades de protección y Atrapados en la Tela de Araña- muestran claramente, el primero, el vinculo entre el desplazamiento migratorio irregular forzado y el incremento de la criminalidad del crimen organizado y las pandillas; el segundo muestra, entre otros aspectos, de manera vivencial ese vínculo, mediante relatos de niños, niñas $y$ jóvenes. El drama se convierte en una verdadera pesadilla, ya que no se logra detectar que, a medio plazo, la situación de aguda exclusión social se reduzca ni que el acoso al que está sometida la niñez por parte de las pandillas en las comunidades y en los centros escolares vaya a disminuir.

La desprotección de la niñez ante las amenazas, victimización y violencia de pandillas es parte de las dinámicas comunitarias en las que viven muchos menores de edad y jóvenes, que se entrelazan con factores de exclusión social y configuran riesgos para este grupo poblacional. Abundan los relatos de jóvenes, como el siguiente de joven entrevistado en México, quien tiene estatus de refugiado en dicho país: "... me empezaron a molestar y todo eso queriéndome involucrar en las maras, nunca me gustó eso, nunca me llamó la atención... Bueno, pasé un año bien, cuando entré al bachillerato fue cuando comenzaron más los problemas, ahí sí me presionaban que me metiera a las maras. Cuando les dije que no quería nada de eso, comenzaron a molestarme y varias veces me golpearon dentro de la escuela y me amenazaban con matar a mi mamá, a mi hermano o hacerme algo afuera. Así pasaron todo el año y ya fueron muchas veces y decidí decirle a mi mamá y 
ella decidió que mejor nos fuéramos de El Salvador". Pero la desprotección del Estado salvadoreño ante estos riesgos no es únicamente lo que también ha quedado al desnudo con los acontecimientos que hemos atestiguado en las últimas semanas. Lo es también el desconocimiento real, que existe entre algunos sectores gubernamentales y políticos, sobre las características que el fenómeno ha adquirido para la niñez salvadoreña. El país cuenta con una Ley de Protección Integral de la Niñez y la Adolescencia, de no más de tres años de aprobación y dos de estar en vigencia, en la que el fenómeno de la migración infantil como factor causante, detonante o efecto no está considerado como una realidad instalada de desprotección para la niñez salvadoreña. Tampoco vemos al personal operativo del Consejo Nacional de la Niñez y Adolescencia (CONNA) presente de manera importante y sostenida en los procesos de recepción de niñez retornada ni en los procesos de tratamiento y de reinserción de la niñez migrante. El CONNA ha aparecido en las circunstancias particulares de esta crisis humanitaria. Queda por verse si la actuación apropiada que ha desplegado en las últimas semanas tiene la dinámica de colocar el tema de la migración infantil en el centro de sus preocupaciones. Queda por verse si la protección a la niñez y a la infancia integra de manera importante acciones en el ámbito de la reinserción social de la niñez migrante.

Sin embargo, el drama de la crisis humanitaria que nos presentó el Gobierno norteamericano no solamente ha servido para mostrar la hipocresía propia, sino la ignorancia e hipocresía de algunos que también han querido manipular y utilizar el tema de la "crisis humanitaria" de los niños, para sacar provecho político y también utilizarlos como moneda de cambio en la política internacional. Algunos altos funcionarios del Gobierno han reflexionado en voz alta -por si los Estados Unidos están escuchando- que la aprobación definitiva de los fondos del FOMILOENIO II servirá para revertir la migración hacia los Estados Unidos, ya que este proyecto generaría oportunidades de empleo digno. Dos aspectos resaltan en estas declaraciones. Por un lado, muestran un desconocimiento de las motivaciones de la migración irregular de salvadoreños, en general, y la de la niñez, en particular. Varios estudios nacionales e internacionales han mostrado hasta la saciedad que la falta de trabajo, el desempleo, no es "la causa" de la migración. Parte de ella tiene esa motivación, ciertamente, pero la mayoría de quienes migran lo hacen aun teniendo trabajo. Es significativo el incremento de la migración de los últimos dos años, vinculado a la victimización por el accionar del crimen organizado. El segundo aspecto es el mensaje intencionado de manipular el tema de la migración infantil como moneda de negociación para la aprobación de los fondos del Fomilenio. Surgen indudablemente interrogantes sobre las reales voluntades políticas y capacidades de los principales gobernantes, de desarrollar una visión integradora y humanista sobre el accionar de las instancias estatales para abordar la problemática compleja de la protección de la niñez, la defensa de sus derechos como migrantes y de su reinserción al momento del retorno. Todavía el episodio de la crisis "made in USA" no ha sido superado, los debates en torno al tema continúan en la política doméstica norteamericana y el retorno de varias centenas de nuestros niños, ahora en el centro de esa crisis, pronto dará inicio. 
Por último, conviene señalar algunas dificultades que emanan de las políticas de migración cuando están enmarcadas dentro de la doctrina o política de seguridad nacional, como es el caso de México y los Estados Unidos. Los problemas asociados a seguridad nacional se conciben como amenazas, ya sea a la integridad territorial o a la convivencia social pacífica. Desde ese punto de vista, los inmigrantes indocumentados representan un riesgo para la seguridad del país. iNiños y niñas indocumentados que llegan exhaustos a la frontera sur de los Estados Unidos representan un verdadero peligro para la seguridad de México y los Estados Unidos! Esto es difícil de creer. Eso alimenta la xenofobia y permite arbitrariedades y abusos de parte de las autoridades migratorias. No hay que olvidar que la detención, el encarcelamiento, la suspensión de los derechos humanos y del debido proceso, y, con frecuencia, la deportación son actuaciones preferenciales cuando un Estado considera comprometida su seguridad. El Gulag, las prisiones en la base norteamericana de Guantánamo y en Abu Grahib, son ejemplos que, a pesar de ser extremos, son consistentes con esa visión de seguridad del Estado. Lo que se necesita es enmarcar las políticas migratorias dentro del contexto de los derechos humanos, el concierto de protocolos internacionales que abordan esos complejos fenómenos humanos y, en el caso de niños, niñas y adolescentes, tomando en cuenta su interés superior. 